\title{
URBANIZACIJA STRAHA OD ZLOČINA
}

\author{
Aleksandra Ilić ${ }^{1}$, Božidar Banović ${ }^{2}$ \\ $\mathrm{UDK}=364.624 .6: 343.6(1-21)$ \\ https://doi.org/10.18485/fb_ubur.2018.1.ch3 \\ ${ }^{1}$ Fakultet bezbednosti, Univerzitet u Beogradu, alex.mag.ilic@gmail.com \\ ${ }^{2}$ Fakultet bezbednosti, Univerzitet u Beogradu, bbvsup@gmail.com
}

\section{Sažetak}

U radu autori razmatraju fenomen straha od zločina, povezujući ga sa urbanizacijom kao globalnim fenomenom i ukazujući na značaj bavljenja tom problematikom. Pod uticajem masovnih medija pojedinci imaju sklonost da preuveličavaju opasnosti, što često vodi pojavi strahova. Takva percepcija rizika je subjektivna i uglavnom je iracionalne prirode.

$\mathrm{S}$ druge strane, kada se strah od zločina razmotri u kontekstu procesa urbanizacije, dobija se nova, drugačija dimenzija problema. U vezi s tim se razmatra i povezanost rizika od kriminaliteta i straha od zločina u gradovima, s obzirom na okolnost da javnu sliku kriminaliteta u gradovima karakteriše isticanje različitih rizika, koji se takođe tretiraju na globalni način. Pod uticajem globalizacije rizika brišu se razlike između ljudi. Iako živimo različite živote, delimo zajednički svetski rizik. Imajući sve to u vidu, može se izvesti zaključak da su dominacija javne slike zločina koja se vezuje za gradska područja i naglašavanje urbanih rizika doveli do pojave urbanizacije straha od zločina. Takav strah je specifičan i u pogledu konkretnih manifestacija, poput straha od masovnih okupljanja u gradovima zbog opasnosti od terorističkih napada ili predatorskog uličnog kriminaliteta, koji se takođe vezuje za gradove.

Iracionalna komponenta straha od zločina dobija nešto drugačiju dimenziju ukoliko se razmatra u sklopu procesa urbanizacije. Percepcija urbanih rizika i usmerenost ka njihovoj kontroli oblikuje i reakciju građana. Ti rizici se opažaju na globalnom nivou, što znači da su apstraktni, pa je samim tim i njihova kontrola otežana. Najlakše je manipulisati takvim rizicima, jer usmerenost javnosti ka tačno određenim urbanim rizicima oblikuje strah od zločina, koji je u odnosu na većinu ljudi iracionalan, a istovremeno njegova prisutnost slabi sposobnost uočavanja rizika kojima su realno izloženi.

Autori na kraju ističu da bi rešenje problema trebalo tražiti u adekvatnom i potpunom informisanju javnosti o različitim rizicima i mogućnostima njihove kontrole, kao i stvarnim razmerama pojedinih oblika kriminaliteta koji izazivaju najveću pažnju javnosti i utiču na stvaranje straha od zločina. Posebnu ulogu u tom procesu trebalo bi da imaju oni koji se profesionalno bave kriminalitetom, bilo u praktičnom smislu (sudije, tužioci, advokati), bilo u teorijskom (naučno bavljenje ovom problematikom), uz nezaobilaznu saradnju medijâ kao ključnog aktera.

Ključne reči: urbanizacija, strah od zločina, medijsko izveštavanje, rizici, gradovi 


\section{Uvod}

Strah bi trebalo da bude prirodna reakcija ljudi na nadražaje koji zavređuju takvu reakciju, odnosno koji mogu predstavljati stvarnu opasnost za pojedince koji taj strah osećaju. To je racionalan strah. Vojnik koji učestvuje u ratu gaji racionalan strah da će izgubiti život. Učenik koji se nije spremio za kontrolni zadatak uplašen je s razlogom, jer će najverovatnije dobiti slabu ocenu. Primera je svakako dosta.

Međutim, još od najranijeg uzrasta osećamo i tzv. iracionalne strahove, koji, u zavisnosti od životnog doba i iskustva, ali i individualnih karakteristika svake ličnosti, poprimaju različite oblike. Deca se tako često plaše mraka, razdvajanja od roditelja, veštica ili babaroga. I odrasli ljudi mogu imati iracionalne strahove. Neki ne prevaziđu strahove iz detinjstva, pa se oni s vremenom samo produbljuju i menjaju. Drugi ih steknu tokom života, i to najčešće kao vid reakcije na neku neprijatnost koju su doživeli.

Neki traumatičan događaj uglavnom bude okidač za takav strah, ali on može nastati i bez toga. Ukoliko je neko npr. imao neprijatno iskustvo pri letu avionom, čak iako objektivno nije postojala opasnost, u budućnosti može početi da oseća strah od letenja. Neko će osećati taj strah i pre prvog takvog putovanja, najverovatnije kao rezultat spoljašnjih nadražaja, prvenstveno zbog medijskih izveštaja o avionskim nesrećama.

Tako dolazimo do one vrste straha koji nas interesuje, a to je strah od zločina. Poput straha od letenja, i strah od zločina je uglavnom iracionalne prirode, podstaknut pre svega odgovarajućim medijskim pričama. Svakako postoje pojedinačni slučajevi osoba koje imaju racionalan strah od zločina, poput situacije kada neko živi sa nasilnikom, ali su ti slučajevi procentualno retki u odnosu na masovnost pojave kakva je strah od zločina. Drugim rečima, strah od zločina može biti racionalan i iracionalan, u zavisnosti od toga da li je utemeljen u objektivnim okolnostima, odnosno da li je rizik od viktimizacije stvarno prisutan. To otvara pitanje mogućnosti individualne procene rizika od viktimizacije kao objektivne kategorije.

S druge strane, kada se strah od zločina razmotri u kontekstu procesa urbanizacije, dobija se nova, drugačija dimenzija problema. U tom smislu, u literaturi se strah od zločina najviše povezuje sa životom u gradovima odnosno ističu se rizici gradske sredine na pojavu zločina. U skladu s tim je i medijska slika zločina, koju karakterišu izveštaji o krivičnim delima koji se pretežno dešavaju u gradovima odnosno ističu se urbane karakteristike zločina. Dominacija takve javne slike zločina i kriminaliteta dovela je do širenja odgovarajućeg straha od zločina.

Problem s takvom javnom slikom zločina i povezanim strahom ogleda se u tome što oba fenomena imaju globalne karakteristike. Najlakše je manipulisati takvim rizicima, jer su ograničene mogućnosti njihovog objektivnog saglédanja od strane većine građana. Slike terorističkih napada u gradovima zahvaljujući medijima munjevitom brzinom obilaze ceo svet $i$ istom brzinom utiču na pojačavanje urbanog straha od zločina. Takav strah od zločina postaje sveobuhvatan, pošto počinju da ga osećaju i oni ljudi koji objektivno nemaju razlog za to. 


\section{Strah od zločina}

Za proučavanje fenomena straha od zločina kriminolozi su se prvi put zainteresovali 60-ih i 70-ih godina prošlog veka, i to kao rezultat razvoja viktimoloških istraživanja, kao što je Britanski pregled kriminaliteta (British Crime Surveys). ${ }^{1} \mathrm{U}$ teoriji se mogu pronaći različite definicije straha od zločina. Jedna od njih određuje ovaj pojam kao racionalno ili iracionalno stanje panike ili uznemirenosti kod nekog lica koji su izazvani verovanjem kako je u opasnosti da bude viktimizovano zločinom. ${ }^{2}$ Neki autori su ukazivali na potrebu razlikovanja straha (emocije) od percepcije/procene rizika viktimizacije, dok su drugi isticali da strah od kriminaliteta predstavlja upravo kombinaciju kognitivnog (procena rizika) i emocionalnog elementa. ${ }^{3}$

$\mathrm{Na}$ pojavu straha od zločina mogu uticati mnogi činioci. U literaturi se može pronaći stav po kojem se ti činioci razvrstavaju u dve grupe: makročinioci (u pitanju su ranija dela, pogodnosti za zločin, organizacija zajednice, koja bi obuhvatala medije, sredina u kojoj se živi, uticaj vršnjakâ) i mikročinioci (reč je o faktorima koji utiču na ocenu pojedinca o rizicima njegove lične viktimizacije, ličnom saznanju o viktimizaciji drugih i sredstvima koja ima na raspolaganju kako bi se suprotstavio potencijalnom ugrožavanju). ${ }^{4}$

Strah je generalno postao sveobuhvatan, budući da više ni u jednoj društvenoj oblasti ne postoji perspektiva straha, već je strah prerastao u ono osećanje koje upravlja javnošću. Zbog toga se u teoriji često iznosi tvrdnja da se današnje društvo može najbolje opisati kao „kultura straha“. Drugim rečima, strah je postao kulturno uslovljena lupa kroz koju posmatramo svet. ${ }^{5}$

U vezi s tim treba ukazati da postoji razlika između ranijih i sadašnjih strahova. Raniji strahovi, koji su nazvani paralelni strahovi, odnosili su se na tačno određene opasnosti i bili su lokalizovani, momentani i individualni. Suprotno tome, nove vrste strahova su tzv. neparalelni strahovi i oni su opšti, prožimaju sve i nisu koncentrisani na nešto konkretno. ${ }^{6}$

Najveću odgovornost za masovnu pojavu straha od zločina imaju mediji. Oni utiču na stvaranje predrasuda, pogrešnih shvatanja i stereotipa u vezi s kriminalitetom, što prvenstveno pogoduje nastanku moralne panike na koju se nadovezuje i strah od zločina. Kampanje o podizanju svesti o zločinu u cilju unapređenja javne bezbednosti često su ocenjene kao slabe, jer povećavaju osećaj nesigurnosti i

1 Marsh, I., and Melville, G., Crime, Justice and The Media, Routledge, London, str. 187.

2 Eugene McLaughlin (2001): Hate crime, in: The Sage Dictionary of Criminology (McLaughlin and Muncie, eds.), London, navedeno prema: Ignjatović, Đ., Kriminologija, Pravni fakultet u Beogradu, Beograd, 2015, str. 149.

3 Ignjatović, Đ., i Simeunović-Patić, B., Viktimologija, Pravni fakultet u Beogradu, Beograd, 2011, str. 108.

4 Ignjatović, Đ., Kriminologija, op. cit., str. 149.

5 Svensen Laš Fr. H., Filozofija straha (Frykt, Oslo, prevodilac Rajić, Lj.), Geopoetika, Beograd, 2007, str. 16.

6 Critcher C., For a political economy of moral panics, Crime Media Culture, SAGE, 2011, str. 263. 
negativno utiču na kvalitet života svih građana. Rizik je postao nadmoćno negativna pojava u kontroli kriminaliteta. ${ }^{1}$

Nije neophodno vršiti istraživanja straha od zločina kako bi se izveo zaključak da postoji značajna veza između načina na koji mediji izveštavaju o kriminalitetu i karakteristika straha od zločina koji građani osećaju. Mediji prenaglašeno izveštavaju o nasilničkom, a potcenjuju imovinski kriminalitet. U tom smislu i građani uglavnom strahuju da ne postanu žrtve nasilja, dok ih imovinski kriminalitet ne brine posebno. Iako su mnogobrojna istraživanja o strahu od zločina potvrdila prethodnu konstataciju, iskrsava jedan metodološki problem u vezi sa njihovim sprovođenjem. Naime, postavljanje pitanja u sklopu istraživanja može uticati na ispitanike da postanu svesniji straha od zločina, a to će ih učiniti spremnijim da priznaju da imaju takve strahove. ${ }^{2}$

Takođe, pojedina istraživanja uticaja medija na strah od zločina ukazala su na to da karakteristike auditorijuma (pol, godine i sl.) i iskustvo (pre svega ranija viktimizacija) mogu imati značajnu ulogu u tome kako se primaju medijski sadržaji. Razumevanje medijskih poruka je dinamičan proces u kojem gledaoci ili čitaoci aktivno interpretiraju i možda rekonstruišu te poruke u svetlu svojih ličnih sposobnosti i iskustva. ${ }^{3}$ Takođe, pojedini autori postavljaju pitanje da li se ljudi plaše zločina zato što se toliko prikazuje u medijima ili mediji toliko izveštavaju o zločinima zato što se ljudi boje i vole da vide šta se u tom segmentu dešava. ${ }^{4}$ Svakako se može braniti stav da mediji prepoznaju psihološku potrebu ljudi da se bave zločinom na benigni način, konzumiranjem medijskih sadržaja o zločinu, što i jeste društveno prihvatljiv način zadovoljavanja te potrebe.

Ova okolnost ipak ne dovodi u pitanje aktivnu ulogu medija u stvaranju i pojačavanju straha od zločina kod ljudi. U tom smislu, ljudi koji mnogo gledaju televiziju skloniji su od drugih da svoje susedstvo posmatraju kao nesigurno, pa veruju da kriminal raste i da su izloženi opasnosti. ${ }^{5}$ Zločin predstavljen na televiziji delo je stranaca i ludaka koji, u bilo kojem trenutku, vrše nasumičan izbor žrtve iz reda svih građana, a to predstavlja ogromno iskrivljavanje stvarnosti kriminaliteta. ${ }^{6}$

Pogrešno predstavljanje problema kriminaliteta naročito je izraženo u kontekstu gradova. U tom smislu medijski izveštaji o kriminalitetu obiluju slikama zločina karakterističnim za gradove - između ostalog, dominira predatorski nasilnički kriminalitet. S obzirom na to da je povećanje broja stanovnika u gradovima nezaustavljiv i kontinuiran proces treba posebno obratiti pažnju na ovaj specifičan oblik

1 Ibidem

2 Wolhuter, L., Olley, N., and Denham, D., Victimology: Victimisation and Victims' Rights, Routledge-Cavendish, 2009, str. 46.

3 Weitzer, R., and Kubrin, E. C., Breaking News: How Local TV News and Real-World Conditions Affect Fear of Crime, in: Constructing Crime: Perspectives on Making News and Social Problems (Potter, W. Gary, and Kappeler, E. Victor, eds.), Illinois, 2006, str. 346 i 347.

4 Marsh, I., and Melville, G., op. cit., str. 188.

5 Svensen Laš, Fr. H., op. cit., str. 25.

6 Howitt, D., Crime, the Media and the Law, Wiley-Blackwell, Chichester, 1998, str. 45. 
straha od zločina koji pogađa veliki broj ljudi. Medijsko izveštavanje o zločinima koji su izvršeni u gradskim područjima ističe urbane karakteristike zločina. To se vrši na takav način da ljudi počinju da se plaše ne samo određenih zločina već i veruju da ih život u gradovima čini ranjivijim, odnosno da su zbog toga više u riziku da postanu žrtve.

Činjenica je da postoji vrlo mala šansa da neko postane žrtva nasilničkog kriminaliteta, bez obzira na sredinu u kojoj živi, a naročito onih oblika koji su najzastupljeniji u medijima. Podesan primer toga kako jedna televizijska emisija može doprineti stvaranju straha od nasilničkog kriminaliteta predstavlja Crimewatch UK, najpoznatiji program na britanskoj televiziji koji se bavio rekonstrukcijom „stvarnog" kriminaliteta. Iako je zamisao urednika ove emisije bila da se na taj način pomogne policiji u rešavanju zločina, odnosno da se alarmiraju gledaoci da i oni učestvuju u tome, stil prikazivanja koji je ličio na krimi-fikcije za posledicu je imao povećan strah od zločina. Ti zločini su izgledali tako stvarno da su gledaoci imali utisak kao da su oni deo njega. Strah od zločina i medijska tvrdnja da se nešto dogodilo stvara zaključan svet opasnosti i pojačava zatvorenost gledalaca. ${ }^{1}$

\section{Povezanost rizika od kriminaliteta i straha od zločina}

Reč rizik potiče od latinske reči risicare, koja znači usuditi se. To izvorno značenje ukazuje da je rizik povezan s odabiranjem, kao nešto što biramo da preduzmemo. ${ }^{2}$ Taj izbor može da bude pozitivan i negativan, pri čemu je najbitnije da predstavlja rezultat naše voljne radnje. Za razliku od ranijih vremena, kada su rizici bili povezani i mogli su se predvideti, u današnje vreme je sve obrnuto, budući da postoji nepovezanost rizika i nepredvidivost u pogledu mogućnosti njihovog proračuna. Rizici uglavnom predstavljaju nepredviđene i neželjene rezultate novih tehnologija: nuklearni, hemijski, ekološki, biološki i medicinski rizici. ${ }^{3}$ Primeri su mnogobrojni: globalno zagrevanje, razni virusi (ebola, HIV, AH1N1 (svinjski grip, ptičji grip...), nuklearne eksplozije itd.

Čim priča o nekom konkretnom riziku završi u medijima, otvara se veliki prostor za različite manipulacije. Uticaj na javno mnjenje lako je ostvariti ukoliko postoji neka potencijalna opasnost koja se u tom cilju može iskoristiti. Iako rizik predstavlja samo moguću pretnju, on se može ostvariti, a sama ta mogućnost je dovoljna da se javnost ubedi u ono što odgovara subjektu koji manipuliše tim rizikom. Na taj način se stvara utisak kao da je došlo do realizacije tog rizika, kao da se već dogodila katastrofa.

1 Kidd-Hewitt, D., Kriminalitet i mediji: kriminološka perspektiva (prevod dela: Crime and the Media: a criminological perspective, London, prevodilac Ilić, A.), in: Ignjatović, Đ., Teorije u kriminologiji, Pravni fakultet u Beogradu, Beograd, 1995, str. 422 i 423.

2 Svensen Laš, Fr. H., op. cit., str. 57.

3 Goode, E., and Yehuda, B., Moral Panics - The Social Construction of Deviance, Wiley-Blackwell, Chicester, 2009, str. 81. 
Bitno je stvoriti utisak da su potencijalno buduće katastrofe u stvari sadašnjost koja se mora sprečiti preduzimanjem odgovarajućih mera. Iako deluje apsurdno, ovaj mehanizam funkcioniše. Ovo je fenomen koji se može dešavati kako na globalnom nivou, tako i u okviru neke konkretne države i može se ispoljiti na različite načine. Kada ostvare takav utisak, manipulatori mogu da rade šta hoće (npr. da ubede javnost u neophodnost preduzimanja mera koje bi trebalo da minimizuju konkretan rizik). Inscenirana anticipacija razaranja i katastrofa obavezuje na preventivno delovanje. ${ }^{1}$ Mere se ne promovišu radi stvarne dobrobiti društva, već, pre svega, u cilju realizacije sopstvenih interesa. ${ }^{2}$

Razvoj tehnologije i sveopšta modernizacija olakšavaju život savremenom čoveku, ali istovremeno stvaraju nove rizike i povećavaju zatečene. Osim povećanja rizika, modernizacija povećava i svest ljudi da su izloženi riziku. ${ }^{3}$ Čovek po prirodi stvari svakako poseduje svest o riziku, jer nam je život nepredvidiv, ali nam ta svest često daje sistematski iskrivljenu sliku sveta. ${ }^{4}$ Subjektivna percepcija rizika uglavnom je iracionalne prirode i ona pre svega počiva na neadekvatnim informacijama kojima ljudi raspolažu. ${ }^{5}$

Građani u društvu rizika žive s onom vrstom straha koji se manifestuje kao pogled na svet, što bi značilo da društvo rizika predstavlja kulturu straha kojom se posebno bavio norveški filozof Laš Svensen (Lars Fr. H. Svendsen). ${ }^{6}$ On smatra da ljudi imaju pogrešne predstave o opasnostima kojima smo izloženi zbog psihološke sklonosti da posvećuju veću pažnju negativnim nego pozitivnim zbivanjima, ali i zbog činjenice da većina ljudi ima sasvim slabo razumevanje verovatnoće i više se usredsređuje na najgori mogući ishod nego na ono što je najverovatnije. ${ }^{7}$

$\mathrm{Na}$ koji način su povezani strah i rizik? Perspektivama straha i rizika potrebne su žrtve - bez aktuelnih ili potencijalnih žrtava one gube snagu. ${ }^{8}$ Ako pripa-

1 Bek, U., Svetsko rizično društvo: u potrazi za izgubljenom sigurnošću (Weltrisikogesellschaft: Auf der Suche nach der verlorenen Sicherheit, Suhrkamp Verlag, Frankfurt am Main, 2007, prevodilac: Glišović, Lj.), Akademska knjiga, Novi Sad, 2011, str. 27.

Kao primer anticipacije rizika može da bude naveden slučaj prve epidemije tzv. svinjskog gripa kod nas, krajem 2009. godine (ovo je bio istovremeno i globalni fenomen), kada je rizik od obolevanja fingiran na nivo katastrofe. Nažalost, u vezi s tim konkretnim slučajem, kao, uostalom, i s mnogim drugim, postoji još dosta nedoumica i nepoznatih stvari koje čekaju na svoje razrešenje. Za javnost se izvodi predstava, koja podrazumeva vođenje krivičnog postupka protiv navodno odgovornih ljudi. Međutim, činjenica je da postoji sumnja u pogledu sveobuhvatnosti postupka. Posle insceniranog utiska o katastrofi i neophodnosti primene mera koje katastrofu treba da spreče, ostaje utisak o nepreduzimanju potrebnih koraka kako bi se kaznili svi oni koji su odgovorni za to, kao i mnoga druga fingiranja.

3 Tompson, K., Moralna panika (Moral Panics, 1998, prevodilac Vranić, I.), CLIO, Beograd, 2003, str. 32.

4 Svensen Laš, Fr. H., op. cit., str. 60 i 61.

5 Bek, U., op. cit., str. 27.

6 Svensen Laš, Fr. H., op. cit., str. 54.

7 Ibid., str. 61.

8 Ibid., str. 59. 
damo nekoj rizičnoj grupi (a male su šanse da ne pripadamo nijednoj), onda se moramo suočiti i sa strahom da ne postanemo žrtve. Deo diskursa rizika je i pronalaženje „krivaca“ za opasnost koja nam preti, ali i definisanje žrtava koje dobijaju epitet „nevinih“ i tako mogu biti potpuno oslobođene odgovornosti za situaciju u kojoj se nalaze.

Fizička i socijalna ranjivost smatraju se značajnim generatorima straha od kriminaliteta. Osobe koje se po sopstvenom ili tuđem mišljenju smatraju fizički ranjivim (na primer, deca) strahuju jer veruju kako u kritičnom momentu ne bi bile sposobne da se odbrane od napada. ${ }^{1}$ Zbog toga se najlakše manipuliše opasnostima koje prete deci, ali i starim osobama i ženama. Ove kategorije stanovništva pokazuju najveći strah, bez obzira na činjenicu da ih njihov stil života stavlja na poslednje mesto na skali verovatnoće da postanu žrtve nasilja. ${ }^{2}$

Strahovi su uvek usmereni na nešto ili nekoga, a i sama moralna panika podrazumeva postojanje određene pretnje koja je materijalizovana. U skladu s konceptom rizičnog društva, pojedinici ili grupe koje su označeni kao „rizične osobe“ ili „rizične grupe“ smatraju se neosobama. S obzirom na dodeljeni epitet, te osobe ili grupe se obeležavaju i etiketiraju, što dovodi do ugrožavanja njihovih ljudskih prava. ${ }^{3}$ Imajući u vidu povezanost rizika i strahova, u teoriji postoji mišljenje kako bi sociološka analiza trebalo da se više bavi problemima rizika i straha od rizika, što se donekle podudara s pristupom moralnoj panici u svetlu politike anksioznosti. Takva sociološka analiza bi se mogla nazvati sociologijom „društva rizika“. ${ }^{4}$

Nasuprot iracionalnom opažanju rizika stoji naučni pristup proučavanju rizika, koji se posmatra kao objektivni fenomen. Problem subjektivnog doživljaja rizika tako se jednostavno može rešiti potpunim i tačnim informisanjem javnosti. No, teza o fingiranju stvarnosti rizika, koja dominira u savremenom društvu, odnosno u svim njegovim bitnim segmentima, a naročito u politici i ekonomiji, ukazuje kako je nerealistično očekivati da javnost može biti objektivno informisana. Globalna anticipacija katastrofe u velikoj meri se opire metodama naučnog izračunavanja. ${ }^{5}$

Međutim, što se opasnost teže može izračunati, to veći značaj dobijaju opažanja rizika, koja variraju od kulture do kulture, što dovodi do zamagljivanja razlike između rizika i kulturom uslovljene percepcije rizika. Drugim rečima, pod uticajem globalizacije rizika brišu se razlike između ljudi. Te razlike mogu da budu nacionalne, rasne, verske i mnoge druge, ali nam globalizacija nameće zajedničko učestvovanje u subjektivnom opažanju svetskog rizika.

Iako živimo različite živote, delimo zajednički svetski rizik. U segmentima života koji su obuhvaćeni tom globalizacijom imamo zajedničku stvarnost sa svim ljudima na planeti, ali se ta stvarnost ne zasniva na zajedničkoj prošlosti i ne garan-

1 Ignjatović, Đ., i Simeunović-Patić, B., op. cit., str. 109.

2 Wolhuter, L., Olley, N., and Denham, D., op. cit., str. 46.

3 Bek, U., op. cit., str. 34.

4 Tompson, K., op. cit., str. 32.

5 Bek, U., op. cit., str. 28. 
tuje zajedničku budućnost. ${ }^{1}$ Globalizacija možda olakšava ljudima da upoznaju nove kulture, ali ona umanjuje vrednost tog putovanja, pošto kulture sve više počinju da liče jedna na drugu. ${ }^{2}$

Treba pomenuti i to da su rizici i njihova kontrola pogodne teme za različite političke manipulacije, a naročito u vreme predizbornih kampanja. Uspešno vladanje predstavlja balansiranje temom rizika. S jedne strane je potrebno održavati optimalnu tenziju među građanima u pogledu mnogobrojnih opasnosti, kako bi se, s druge strane, mogla istaći strategija kontrole tih rizika. Ubeđivanjem javnosti u efikasnost predloženih mera dobijaju se potrebni politički poeni i u tom smislu je

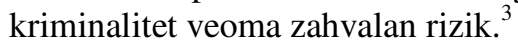

\subsection{Rizik od kriminaliteta u gradovima}

Diskurs o zajedničkim rizicima od kriminaliteta - globalizacija rizika - briše razlike između ljudi. Rizik od kriminaliteta je, izgleda, jedna od najvažnijih zajedničkih karakteristika svih ljudi na planeti, barem je to slika koju nam mediji svakodnevno šalju. Pored globalizacije rizika od kriminaliteta, postoji tendencija medijskog potenciranja tačno određenih rizika koji su povezani sa životom u gradovima. U tom smislu se naročito ističu rizici od sledećih oblika kriminalnog delovanja: terorizam i nasilnički kriminalitet u gradovima.

Globalizacija rizika od terorističkog napada posle 11. septembra 2001. godine utiče na živote svih ljudi na svetu koji putuju avionom. Svet je bio u šoku nakon tog događaja, iako su mnoge druge zemlje, poput Velike Britanije, mnogo pre toga iskusile terorističke napade. ${ }^{4}$ Međutim, odgovor napadnute Amerike bio je toliko dominantan da je doveo do anticipacije rizika od terorističkih napada na svetskom nivou. U međunarodnim okvirima objavljen je ,rat protiv terorizma“, rat koji će mobilisati i „srca i umove“. 5 .

Nametnuta su određena pravila ponašanja, bez obzira na drugačije okolnosti koje postoje u pojedinim oblastima odnosno državama. Jedna od osnovnih odlika društva rizika jeste da niko nije bezbedan - apsolutno svi mogu da budu pogođeni, bez obzira na društveni status. ${ }^{6}$ Medijske slike terorističkih akata i svakodnevni izveštaji dovode do globalizacije straha od terorizma, koji se obično povezuje sa životom i boravkom u gradovima. To kao posledicu ima globalnu percepciju gradova kao nesigurnih područja, što utiče na donošenje odluka pojedinaca u vezi sa planiranjem putovanja i boravkom u gradskim sredinama.

1 Ibid., str. 29.

2 Brigs, A., i Berk, P., Društvena istorija medija: od Gutenberga do Interneta (prevod dela: A Social History of the Media, prevodilac: Đorđević, J., 2005, Cambridge), CLIO, Beograd, 2006, str. 434.

3 O'Malley, P., Crime and risk, SAGE, 2011, str. 13.

4 Brigs, A., i Berk, P., op. cit., str. 436.

5 Ibidem

6 Svensen Laš, Fr. H., op. cit., str. 56. 
S druge strane, pojavljuje se prenaglašenost rizika od nasilničkog kriminaliteta u gradovima, pri čemu najveći strah osećaju posebno osetljive grupe (žene, deca i stari ljudi), iako objektivno imaju manje razloga za to u odnosu na muškarce u mlađim i srednjim godinama. $\mathrm{U}$ tom smislu treba istaći problem zanemarivanja nasilničkog kriminaliteta, koji nije nužno povezan sa životom u gradu (silovanje od strane poznate osobe, pedofilija koju čine osobe bliske deci i dr.). Medijsko insistiranje na urbanim karakteristikama zločina skreće pažnju sa onih zločina koji te karakteristike nemaju, što umanjuje kapacitet građana da ih prepoznaju i blagovremeno i adekvatno reaguju.

Urbanizacija straha od zločina utiče na potcenjivanje rizika od imovinskog kriminaliteta, koji se može razmotriti sa dva aspekta. Medijski izveštaji o imovinskom kriminalitetu uglavnom se odnose na specifični obilik ispoljavanja tog oblika kriminaliteta. U pitanju su ona imovinska krivična dela čije činjenje karakteriše upotreba nasilja, poput razbojništva i razbojničke krađe. Ta dela se u kriminološkoj literaturi smatraju oblicima nasilničkog kriminaliteta, i to tradicionalnog, pored ubistva, telesnih povreda i različitih oblika seksualnih delikata. ${ }^{1} \mathrm{~S}$ druge strane, krivično pravo svrstava razbojništvo i razbojničku krađu u grupu krivičnih dela protiv imovine. ${ }^{2}$ Razbojništvo i razbojnička krađa nikako nisu tipična imovinska krivična dela ne samo kad su u pitanju gradovi, ali medijski izveštaji tvrde suprotno, čime stvaraju pogrešnu sliku o osobinama i razmerama imovinskog kriminaliteta.

„Pravi“ urbani imovinski kriminalitet medijima nije interesantan. Naročito se zanemaruje rizik od posebnog oblika krađe koji je karakterističan za gradove i javni prevoz, odnosno svako gradsko područje gde se nalazi veći broj ljudi. U pitanju je džepna krađa. Termin džepna krađa nije krivičnopravni, već kriminalistički, jer ukazuje na uobičajen način izvršenja dela, tj. iz džepa žrtve. Džepna krađa predstavlja oduzimanje tuđe pokretne stvari iz odevnih predmeta oštećenog ili njegovog prtljaga. Zavisno od načina izvršenja, okolnosti i visine oštećenja, džepna krađa može, u krivičnopravnom smislu, biti kvalifikovana kao obična ili teška krađa. $^{3}$

Mnogo ljudi koji se voze gradskim prevozom barem jednom su bili odžepareni i to je za mnoge od njih jedini oblik viktimizacije koji su pretrpeli tokom života, ali ta okolnost uglavnom ne utiče bitno na percepciju stvarnosti o kriminalitetu. Takođe, statistički gledano, takvi oblici krađe, koji s obzirom na vrednost stvari obično spadaju u sitna dela krađe, veoma su brojni, a postoji i izražena tamna brojka kriminaliteta, jer većina ljudi i ne prijavljuje da su oštećeni na ovaj način. Ipak, džepna krađa, s obzirom na način izvršenja, može biti kvalifikovana i kao teška krađa. U suštini se radi o ne tako bezazlenom fenomenu koji se u javnosti zanemaruje.

1 Ignjatović, Đ., Kriminologija, op. cit., str. 112.

2 Krivični zakonik (Službeni glasnik RS, br. 85/05, 88/05 - ispr., 107/05 - ispr., 72/09, 111/09, 121/12, 104/13 i 108/14).

3 Žarković, M., Banović, B., Stupar, Lj., i Ivanović, V., Kriminalistika, Beograd, Viša škola unutrašnjih poslova, 1997, str. 154. 
Globalni rizik svojom medijskom sveprisutnošću posvakidašnjuje smrt i patnju, i to ne samo kao pojedinačnu već i kao kolektivnu sudbinu, uprkos tome što će za većinu ljudi to značiti poistovećivanje sa slikama tuđe patnje. ${ }^{1}$ Problem s takvim globalnim poistovećivanjem, koje se odvija putem medijskog prenosa patnje, jeste što se dešava u virtuelnom svetu, tako da nije moguće stvarno i neposredno osetiti tu patnju ili opaziti rizik. Mediji to predstavljaju na takav način da ,potrošači“ informacija imaju utisak da smo i sami deo tog konteksta. Ošamućenost globalnim rizicima može dovesti do toga da se previdi neki daleko opasniji pojedinačni rizik.

Takođe se može dogoditi nešto drugo. Postoje ljudi koji teško podnose taj pritisak koji nameće društvo rizika, tu stalno prisutnu tenziju da će se neki rizik ostvariti. Takvi ljudi imaju snažnu potrebu da upravljaju rizicima koji ih okružuju. U pokušajima da kontrolišu rizike, ti ljudi često biraju sredstva koja su gora od problema koji žele da reše. ${ }^{2}$

\section{Uticaj medijske slike rizika od kriminaliteta}

Savremeni oblici vladanja neraskidivo su povezani s idejom kontrolisanja reakcije javnosti na mnoge fenomene. Jedan od fenomena koji uvek izaziva pažnju javnosti jeste kriminalitet. Mogućnost manipulacije temom kriminaliteta zaista je velika, a jedan od načina na koji se to može postići u cilju ostvarenja različitih interesa jeste medijsko predstavljanje kriminaliteta kao rizika. $S$ obzirom na to da je u današnje vreme rizik postao zajednička stvar, nešto što se deli bez obzira na sve različitosti koje postoje između ljudi, tako je i rizik od kriminaliteta opšta i zajednička tekovina savremenog doba.

U teoriji su razmišljanja o riziku uklopljena u širu kulturu nesigurnosti, viktimizacije i straha. Teorijsko bavljenje kriminalitetom, devijantnošću i oblašću socijalne kontrole danas je nezamislivo bez razmatranja dva aspekta u vezi s rizikom: prvi se odnosi na tehnička pitanja analize rizika, a drugi na širu kulturu govora o riziku (risk-talk). ${ }^{3}$ Meri Daglas je razmatrala zabrinutost javnosti zbog kriminala i devijantnosti, tvrdeći da se ono što javnost opaža kao rizično ili zastrašujuće može iskoristiti kao objektiv kojim se izoštrava fokus na samu organizaciju društva. Njena analiza je u skladu s dirkemovskim teorijskim modelom, prema kojem moralni kosmos koji kažnjava koristi rizike da bi održao zajedništvo. ${ }^{4}$

Svakodnevno smo svedoci prakse izvlačenja koristi iz kriminalnih dešavanja od strane onih koji zauzimaju određene pozicije moći u društvu. Kriminalitet,

1 Bek, U., op. cit., str. 29 i 30.

2 Svensen Laš, Fr. H., op. cit., str. 57.

3 Cohen, S., Folk Devils and Moral Panics: The Creation of the Mods and Rockers, Routledge, London, 1971, str. xxxi

4 Tompson, K., op. cit., str. 32 i 33. 
nažalost, koristi političarima, koji osvajaju poene na osnovu nekih aktuelnih slučajeva. Oni će rado usvojiti populistički program ,reda i mira“ onda kada je javno mnjenje podstaknuto medijskim pričama o povećanju rizika zbog opasnosti koju nosi društveno devijantno ponašanje. ${ }^{1}$ Javni nastupi političara samo doprinose održavanju i pojačavanju nerealistične subjektivne percepcije koju građani neguju o zločinu.

Posebno pitanje je kako takva javna slika kriminaliteta utiče na percepciju građana o stanju kriminaliteta u društvu i na koji način utiče na pojavu straha od zločina. U vezi sa tim će se ovde izneti pojedini rezultati istraživanja koje je sprovedeno u cilju utvrđivanja razmera i karakteristika tog uticaja.

Ispitivanje stavova građana preduzeto je u formi ankete koja je sprovedena na uzorku od 160 građana. U pitanju su uglavnom stanovnici Beograda, iz različitih gradskih opština. Prilikom formiranja uzorka prvenstveno se vodilo računa da budu u što većoj meri zastupljene različite kategorije stanovništva.

U kontekstu teme koja se obrađuje u ovom radu treba pomenuti dominantan stav građana u pogledu tvrdnje koja se često ističe u medijskim izveštajima. To je tvrdnja o stalnom porastu kriminaliteta u Srbiji. Ispitani građani su u velikom procentu (75\%) zaokružili odgovore ,slažem se“ i ,u potpunosti se slažem“.

Tabela 1

Porast kriminaliteta u Srbiji

\begin{tabular}{|l|r|r|r|r|}
\hline & Frequency & Percent & $\begin{array}{c}\text { Valid } \\
\text { Percent }\end{array}$ & $\begin{array}{c}\text { Cumulative } \\
\text { Percent }\end{array}$ \\
\hline u potpunosti se slažem & 53 & 33,1 & 33,1 & 33,1 \\
\cline { 2 - 5 } slažem se \\
ne slažem se \\
\cline { 2 - 5 } $\begin{array}{l}\text { uopšte se ne slažem } \\
\text { ne znam }\end{array}$ & 67 & 41,9 & 41,9 & 75,0 \\
\cline { 2 - 5 } Total & 13 & 8,1 & 8,1 & 83,1 \\
\cline { 2 - 5 } & 25 & 1,3 & 1,3 & 84,4 \\
\cline { 2 - 5 } & 160 & 100,0 & 15,6 & 100,0 \\
\hline
\end{tabular}

Sledeće pitanje je imalo cilj da utvrdi razmere viktimizacije, odnosno utvrđivanje tamne brojke kriminalne viktimizacije nekim nasilničkim krivičnim delom. Među ispitanicima je mali broj viktimizovanih tim oblikom kriminaliteta.

Tabela 2

\begin{tabular}{|rl|r|r|l|}
\hline & Frequency & \multicolumn{1}{|c|}{$\begin{array}{l}\text { Valid } \\
\text { Percent }\end{array}$} & $\begin{array}{l}\text { Cumulative } \\
\text { Percent }\end{array}$ \\
\hline \multirow{3}{*}{ Valid } & $\mathrm{Da}$ & 18 & 11,3 & 11,3 \\
\cline { 3 - 5 } & $\mathrm{Ne}$ & 142 & 88,8 & 100,0 \\
\cline { 3 - 5 } & Total & 160 & 100,0 & \\
\hline
\end{tabular}

1 Ibid., str. 33. 
Malobrojni ispitanici koji su zaokružili „da“ na prethodno pitanje o viktimizaciji $(11,3 \%)$ odgovarali su na sledeće pitanje u cilju utvrđivanja vrste nasilničkog krivičnog dela kojim su ta lica bila viktimizovana. Među ponuđenim odgovorima najviše je zaokruženo ,telesna povreda“ $(50 \%)$, nasilje u porodici $(11 \%)$, neko drugo delo koje podrazumeva nasilje $(38,9)$ dok niko nije bio žrtva seksualnog krivičnog dela.

Sledeće pitanje se nadovezuje na prethodno, jer se tiče utvrđivanja razmera straha od zločina kod građana. U odnosu na $11,3 \%$ ispitanika koji su odgovorili potvrdno na pitanje o viktimizacijskom iskustvu, dvostruko više građana oseća strah od viktimizacije nekim nasilničkim krivičnim delom.

Tabela 3. Viktimizacija nasilničkim krivičnim delom

\begin{tabular}{|rc|r|r|r|r|}
\hline & & Frequency & Percent & \multicolumn{1}{c|}{$\begin{array}{c}\text { Valid } \\
\text { Percent }\end{array}$} & \multicolumn{2}{c|}{$\begin{array}{c}\text { Cumulative } \\
\text { Percent }\end{array}$} \\
\hline \multirow{3}{*}{ Valid } & $\mathrm{Da}$ & 37 & 23,1 & 23,1 & 23,1 \\
\cline { 3 - 6 } & $\mathrm{Ne}$ & 123 & 76,9 & 76,9 & 100,0 \\
\cline { 3 - 6 } & Total & 160 & 100,0 & 100,0 & \\
\hline
\end{tabular}

\section{Zaključak}

Činjenica je da koncentrisanost javnosti na rizik od kriminaliteta skreće pažnju s mnogih drugih aktuelnih tema koje predstavljaju mnogo veći razlog za zabrinutost u odnosu na npr. problem nasilja na sportskim takmičenjima. Što je interesovanje veće za raznorazne rizike, postojeće ili nepostojeće, manje se razmišlja o stvarnim problemima. Pošto većina ljudi nije u mogućnosti da objektivno proceni indvidualni rizik od kriminaliteta uopšte, kao ni rizik od određenih konkretnih formi ispoljavanja kriminalne aktivnosti, razumljivo je da se uglavnom oslanjaju na neproverene informacije koje dobijaju putem medijâ. Subjektivnost rizika se tako širi među laicima, koji se smatraju loše informisanim u poređenju s preciznim i naučnim načinima posmatranja eksperata. Na osnovu toga se može zaključiti da iracionalnost opažanja rizika kod velikog dela građana počiva pre svega na neadekvatnim informacijama. ${ }^{1}$

Iz svega navedenog proizlazi da bi se rešenje problema subjektivnog opažanja rizika moglo pronaći u potpunom i istinitom informisanju javnosti. To ipak nije tako jednostavno, zato što postoji interes, kako medija tako i političara, predstavnika elite i mnogobrojnih uticajnih društvenih grupa, da se održava manipulacija informacijama o kriminalitetu. Javnost koja govori o zanemarivanju dece, seksu-

1 Bek, U., op. cit., str. 28. 
alnom zlostavljanju ili predatorskom uličnom kriminalitetu snažno odoleva jeziku verovatnoća. Statistika po kojoj kao pojedinci snosimo nizak rizik da postanemo žrtve ipak nije mnogo utešnija u odnosu na poruku koju nam šalju rezultati medicinskih istraživanja po kojima pripadamo kategoriji koja je u niskom riziku u pogledu obolevanja od neke bolesti od koje, bez obzira na tu činjenicu, već bolujemo. ${ }^{1}$ U glavama ljudi neće ostati podatak o verovatnoći da se postane žrtva, već samo činjenica da postoji i najmanja mogućnost da se to dogodi, zato što je način izveštavanja takav da proizvodi zabrinutost i strah.

Privid pokušaja da se javnosti pruže odgovarajuće informacije o kriminalitetu postoji onda kada se u medijima objavljuju neki zvanični podaci o stanju kriminaliteta, ali se njihovo značenje iskrivljuje, izvlači iz konteksta, odnosno tumači na način kakav odgovara onima koji su dominantni i kojima je u interesu da građani imaju subjektivni osećaj ugroženosti kad je u pitanju kriminalitet. Jedini koji mogu nešto promeniti u pogledu subjektivne percepcije rizika građana su oni koji se profesionalno bave kriminalitetom bilo u praktičnom smislu (sudije, tužioci, advokati), bilo u teorijskom (naučno bavljenje problematikom kriminaliteta). Međutim, utisak je da se glas stručnjaka u javnosti slabo čuje, što je uglavnom rezultat određene inercije koja je zavladala među njima, ponašanje u skladu s politikom nezameranja i hodanje linijom manjeg otpora. S druge strane, ni mediji nisu mnogo zainteresovani da razbijaju zablude u pogledu rizika, jer im to ne odgovara. Dramatični događaji prodaju priče i povećavaju gledanost, a u skladu sa tim je i kontinuirano održavanje tenzije među građanima.

U sklopu razmatranja ove problematike, treba podsetiti na „koncept kriminologije proizvodnje vesti“, koji je nastao na zaključcima konstitutivnih kriminologa o delimičnoj odgovornosti kriminologâ za način na koji se o kategorijama zločina i njegove kontrole svakodnevno izveštava. Kriminologija proizvodnje vesti trebalo bi da se suprotstavi neadekvatnoj praksi izveštavanja o kriminalitetu tako što bi prevladala mitove, stereotipe i konstrukcije povezane s uobičajenom slikom zločina i pravde. ${ }^{2}$ Kriminolozi bi imali važnu društvenu ulogu u procesu demistifikacije informacija o kriminalitetu koju javnost dobija putem medija. To bi rezultovalo otklanjanjem zabluda i utvrđivanjem istine u pogledu rizika od kriminaliteta, što bi značajno uticalo i na percepciju građana u vezi s tim. Međutim, imajući u vidu vremensku distancu između trenutka kada se ta ideja promovisala i sadašnje situacije u pogledu medijskog informisanja o kriminalitetu, mnogo će vremena proteći dok se ta promena ne dogodi.

1 Cohen, S., op. cit., str. xxxii
2 Ignjatović, Đ., Teorije u kriminologiji, op. cit., str. 108. 


\section{Literatura}

1. Bek, U.: Svetsko rizično društvo: u potrazi za izgubljenom sigurnošću (Weltrisikogesellschaft: Auf der Suche nach der verlorenen Sicherheit, Suhrkamp Verlag, Frankfurt am Main, 2007, prevodilac: Glišović, Lj.), Akademska knjiga, Novi Sad, 2011.

2. Brigs, A., i Berk, P.: Društvena istorija medija: od Gutenberga do Interneta (prevod dela: A Social History of the Media, prevodilac: Đorđević, J., 2005, Cambridge), CLIO, Beograd, 2006.

3. Cohen, S.: Folk Devils and Moral Panics: The Creation of the Mods and Rockers, Routledge, London, 1971.

4. Critcher, C.: 'For a political economy of moral panics', Crime Media Culture, SAGE, 263, 2011.

5. Goode, E., and Ben-Yehuda, N.: Moral Panics: The Social Construction of Deviance, Wiley-Blackwell, Chicester, 2009.

6. Greer, C. and Reiner, R. (2012): Mediated mayhem: Media, Crime, Criminal Justice, in: Maguire M., Morgan R. and Reiner R. (eds.), The Oxford Handbook of Criminology, Fifth edition, Oxford.

7. Howitt, D.: Crime, the Media and the Law, Wiley-Blackwell, Chichester, 1998.

8. Ignjatović Đ., Teorije u kriminologiji, Pravni fakultet u Beogradu, Beograd, 2009.

9. Ignjatović Đ., Kriminologija, Pravni fakultet u Beogradu, Beograd, 2015.

10. Ignjatović Đ., i Simeunović-Patić B., Viktimologija, Pravni fakultet u Beogradu, Beograd, 2011.

11. Marsh, I. and Melville, G.: Crime, Justice and The Media, Routledge, London, 2009.

12. O’Malley, P.: Crime and risk, SAGE, London, 2011.

13. Svensen Laš, Fr. H.: Filozofija straha (Frykt, Oslo, prevodilac Rajić, Lj.), Geopoetika, Beograd, 2007.

14. Tompson, K.: Moralna panika (Moral Panics, 1998, prevodilac Vranić, I.), CLIO, Beograd, 2003.

15. Weitzer, R., and Kubrin, E. C.: 'Breaking News: How Local TV News and Real-World Conditions Affect Fear of Crime', in: Constructing Crime: Perspectives on Making News and Social Problems (Potter, W. Gary, and Kappeler, E. Victor, eds.), Illinois, 2006.

16. Wolhuter, L., Olley, N., and Denham, D.: Victimology: Victimisation and Victims' Rights, Routledge - Cavendish, 2009.

17. Žarković, M., Banović, B., Stupar, Lj., i Ivanović, V., Kriminalistika, Beograd, Viša škola unutrašnjih poslova, 1997.

\section{Pravni propisi}

Krivični zakonik (Službeni glasnik RS, br. 85/05, 88/05 - ispr., 107/05 - ispr., 72/09, 111/09, 121/12, 104/13 i 108/14). 


\section{URBANIZATION OF THE FEAR OF CRIME}

\section{Summary}

In this paper, the authors discuss the phenomenon of fear of crime by linking it with urbanization as a global phenomenon stressing the importance of dealing with this problem. The study of fear of crime began in the 60 s and 70 s of the last century as a result of the development of victimology research. Fear of crime is a condition of anxiety or panic in people driven by the belief that there are chances that they may become victims of a crime. In particular, the question is whether fear of crime involves only the emotional response of individuals, which is independent from the cognitive processes concerning the perception/risk assessment or victimization is the result of the combination of both elements. Starting from the premise that fear of crime is generally not an immediate reaction of the individuals but more lasting feeling, the authors suggest that certain cognitive processes must be actual. In this sense, the fear of crime can be rational and irrational, depending on whether it is justified in objective circumstances or whether the risk of victimization is really present. This opens up the question of the possibility of individual assessment of the risk of victimization as objective category. The great problem of modern man is subjective experience of reality, in particular the risks to which it is exposed. In the absence of adequate information that originates from a trusted source people greatly estimate their position and the dangers that threaten them on the basis of media reports. Under the influence of media people have a tendency to exaggerate the dangers, which often leads to the appearance of fears. Such risk perception is subjective and mostly irrational by nature.

On the other hand, when the fear of crime is considered in the context of urbanization, it offers new and different dimensions of the problem. The fact is that the increase of population in cities is a continuous and unstoppable process that takes place at the global level, regardless of the differences that exist between the different parts of the world and individual countries. In this sense, in the literature the fear of crime is most often associated with the life in cities and highlights the risks of urban environment influencing the occurrence of crime. In line with this is the media image of crime, characterized by the reports of crimes that occur mainly in the cities and emphasize the characteristics of urban crime. The dominance of such public images of crime has led to the expansion of the appropriate fear of crime. The problem with such a public image of crime and related fear is that both phenomena have global characteristics. In this respect the authors consider the connection between the risk of crime and fear of crime in cities considering that the public image of crime in cities is characterized by highlighting the various risks which are also treated to a global way. Under the influence of globalization risks the differences between people are erased. Although we live different lives, we share a common global risk. Bearing all this in mind, it can be concluded that the dominance of the public image of crime is linked to urban areas, and emphasis on urban risk has led to the emergence of urbanization of fear of crime. Such fear is also specific in terms of concrete manifestation such as fear of mass rallies in cities due to the risk of a terrorist attack or predatory street crime, which is also linked to the cities. 
Irrational component of a fear of crime receives a slightly different dimension when considered in the process of urbanization. The perception of urban risks and orientation to their control shape the response of the citizens. These risks are perceived globally, which means that they are abstract and consequently it is difficult to achieve their control. It is easy to manipulate such risks because of limited opportunities of the majority of citizens to consider them objectively. Pictures of terrorist attacks in cities are seen by the whole world, thanks to the media, at lightning speed and at the same speed affect the enhancement of urban fear of crime. Such fear of crime becomes comprehensive, because those people who have no objective reason to do so start to feel it. In the minds of people the information on the likelihood of becoming a victim will not remain, but just the fact that there is even the slightest possibility that this happens because of the media coverage that produces anxiety and fear. The authors point out that because of urbanization of fear of crime the risks of crime that are associated predominantly with rural areas are ignored or risks that exist independently of the environment in which they are expressed. In this sense the risk of property crime is ignored, which is everywhere and always present. However, public focus on certain urban risks shapes fear of crime that is, compared to most people, irrational and at the same time its presence weakens the ability of people to recognize the risks they are really exposed to.

Finally, the authors point out that a solution to the problem should be sought in an adequate and complete information from the public about various risks and opportunities to control them as well as the actual extent of certain forms of crime which draw the greatest public attention and influence the creation of fear of crime. A special role in this process should be given to those who are professionally engaged in crime, in practical terms (judges, prosecutors, lawyers) or in the theoretical way (scientists dealing with the issue of crime) with the inevitable media cooperation as a key actor.

Keywords: urbanization, fear of crime, media reporting, risks, cities 